\title{
CREATING OPEN EDUCATION RESOURCES FOR TEACHING AND COMMUNITY DEVELOPMENT THROUGH ACTION RESEARCH: AN OVERVIEW OF THE MAKERERE AGSHARE PROJECT
}

\author{
John B. Kaneene \\ Michigan State University \\ Stevens Kisaka \\ Makerere University
}

\author{
Paul Ssajjakambwe \\ Makerere University \\ RoseAnn Miller \\ Michigan State University
}

\author{
John D. Kabasa \\ Makerere University
}

\begin{abstract}
The AgShare Phase I Program, conducted at Makerere University, Kampala, Uganda, was formed to create open education resources for teaching and community development through action research. The study was conducted by an interdisciplinary team of investigators from fields of veterinary medicine and agri-business. Two master of science students conducted dairy value chain action research that produced case materials used to create open education resources (OER) course modules (milk hygiene and marketing modules) and design interventions that would improve milk production, quality, and safety; reduce milk spoilage; increase price per liter of milk received by farmers; and support on-farm processing of yogurt and other dairy products. This research was used in partial fulfillment of the requirement for the master's degree in Livestock Development, Planning, and Management (MLD) and the master's degree in Agri-business Management (M Agbus Mgt) by these students. The conceptual design, implementation, monitoring, and impacts of action research on teaching, students learning, and the dairy industry are discussed in detail.
\end{abstract}

\section{KEY WORDS}

Open Education Resources; Action Research; Higher Education; Community Development; Dairy Value Chain; Milk Quality and Safety; Agri-business Management

\section{BACKGROUND}

\section{A. Development Needs}

The Government of Uganda prioritized the agriculture sector in view of the United Nations Millennium Development Goals [1] and consequently identified the dairy industry as one of the top agro-economic sectors to be targeted for improvement. Dairying is one of the enterprises that farmers use to improve their standards of living. It is a developmental enterprise, as it widens and sustains major pathways out of poverty: securing assets for the poor, improving smallholder and pastoral productivity, and increasing market participation by the poor. In Uganda, the dairy industry contributes to about $50 \%$ of the total 
livestock gross domestic product (GDP), which in turn contributes to nearly $20 \%$ of the total agricultural GDP [2]. At household levels, it provides a year-round source of income through the sale of animals and animal products in addition to replenishing soil fertility and improving food security. However, enormous challenges in the dairy industry remain as major barriers to achieving development goals in the agricultural sector. These challenges are largely centered on a lack of competencies among the farmers and of their advisors (i.e., extension staff and civic leaders). With $90 \%$ of milk production in Uganda marketed through informal channels, and with the adulteration of milk (e.g., surface water) reported as a common practice, the need for improved farming and marketing practices is evident.

\section{B. Role of Education in Addressing Development Needs}

Throughout the last century, educational institutions have played a critical role in knowledge and technology transfer and sustainability in African societies. These efforts have put these institutions in a critical position for community development. However, the traditional "ivory tower" approaches to capacity building in Africa by these institutions are largely theoretical and classroom-based, with few evidence-based approaches to teaching the next generation of researchers, teachers, and policy makers. Such approaches to training are inadequate, and these graduates are not well prepared to solve societal challenges in the real world. Field-based case studies are unavailable for teaching, and research to generate new knowledge and technology are limited. The traditional model of classroom-based learning in many institutions in developing countries places emphasis on lectures and examinations, which results in academic staff considering themselves primarily as lecturers. This differs from the paradigm from universities in the United States, where active participation in research is a responsibility of the academic staff. In these institutions, academics consider themselves to be researchers, and they are able to tailor the content of their teaching materials to reflect new research and developments in their academic fields. This dynamic approach to course content makes the academic focus more on teaching new material rather than lecturing on existing (and often outdated) materials.

\section{A New Approach-OER to Address Specific Development Needs in Uganda}

Recognizing the shortcomings of the current educational system in addressing agricultural development needs in Uganda, the first phase of the Agriculture Sharing (AgShare) Program at Makerere University was developed. The goal of AgShare Phase I at Makerere University was to increase dairy production through improved knowledge and skills of stakeholders in all aspects of the dairy value chain. Under the AgShare vision, the model of education at the university level would be shifted from a didactic, lecturebased model to a teaching approach utilizing a continuously updated information loop system of realworld information. At the university level, this information loop would be based on action research conducted in the field in the areas of interest, assessment of results from action research, formulation of intervention strategies to address problems identified in the assessments, and development of open education resources (OER) and other educational resources for teaching students who would participate in action research, thereby completing the teaching cycle.

An important aspect of the AgShare vision is that the dissemination of knowledge, skills, and services to stakeholder communities will also occur through the information loop system for OER-based research (figure 1). Community stakeholders will be active participants in the information loop by participating in action research to identify research needs and providing information and data for studies aimed at improving the performance of the dairy value chain. As intervention strategies are developed to address specific problems, stakeholders will receive training and assistance to implement these interventions, providing feedback on the success of these strategies to be used by researchers to improve future intervention strategies. 


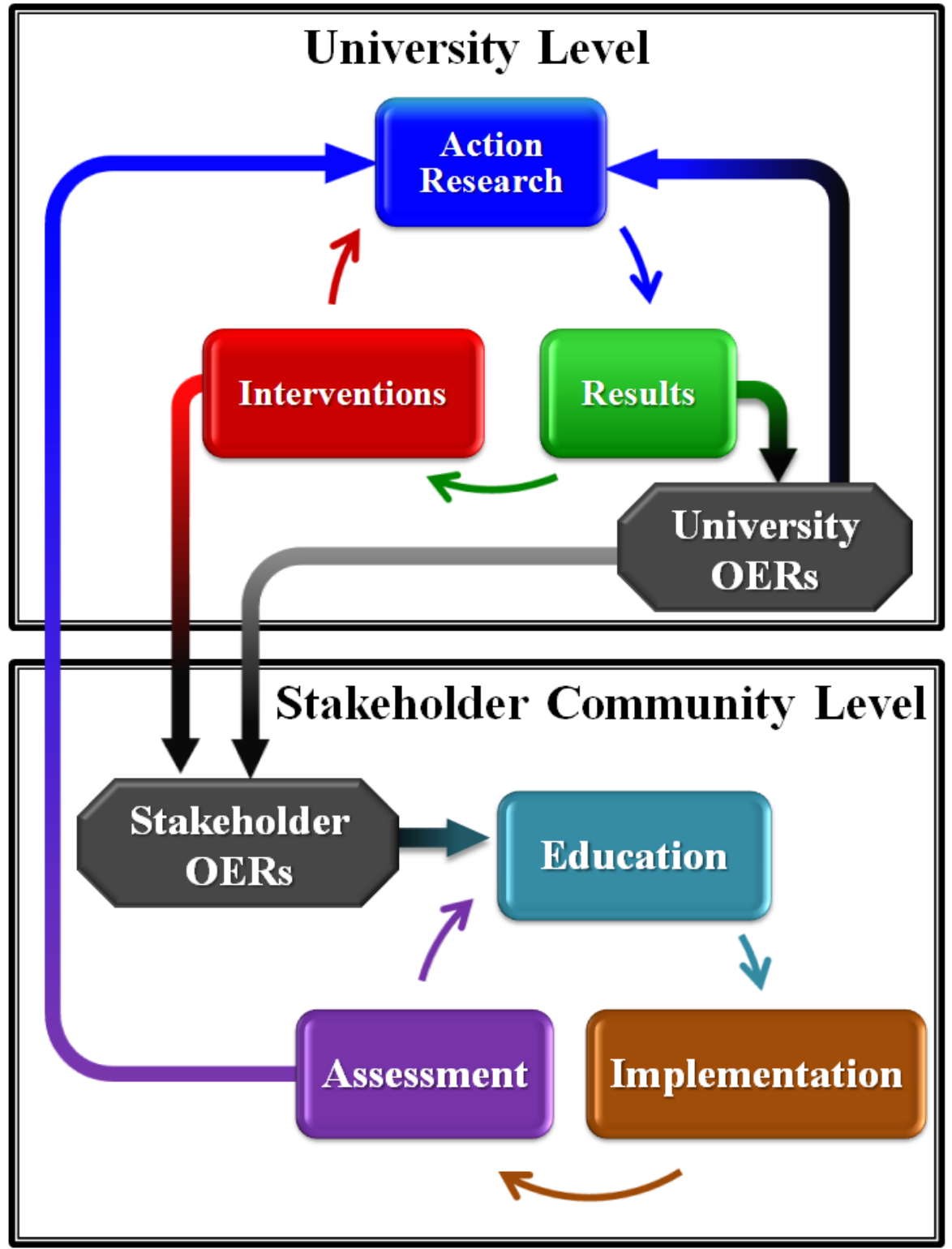

Figure 1.Cycles of OER development and use at the university and stakeholder levels under AgShare.

The feedback loop creates opportunities for ensuring that the educational materials being generated are applicable to real-world situations, and these materials will be constantly updated to meet the changing needs of the stakeholder communities. The training utilizes OER materials developed by university researchers for the AgShare stakeholder partners and will be made available to other interested stakeholders.

Using graduate students as agents of change in the information loop between academia and stakeholders is a critical component of AgShare. Masters-level graduate students training under the AgShare Program would be actively involved in community engagement, participate in action research both in the field and at the university, provide educational materials to stakeholders, aid stakeholders in the implementation of interventions, and serve as a direct line of communication between stakeholders and academics. Research conducted by these students would be used for their masters-level theses, and their findings would be published in refereed scientific journals, which will further spread AgShare research beyond Makerere University and Uganda. The students' direct involvement in stakeholder communities would help their 
academic mentors to appreciate the diversity and dynamism of situations in the field, which would form opportunities for these students to become facilitators of change at both the university and in the field.

\section{DEVELOPMENT OF THE AGSHARE PROGRAM AT MAKERERE UNIVERSITY}

\section{A. Partners in AgShare Phase I}

The goal of the first phase of AgShare was to improve the dairy value chain through utilization of OER using the Kiruhura District, located in southwestern Uganda, as a case study. AgShare Phase I was a collaborative effort between Makerere University (the College of Veterinary Medicine, Animal Resources, and Biosecurity (COVAB) and the College of Agricultural and Environmental Sciences), Michigan State University (the College of Veterinary Medicine and MSU Global Knowledge Innovations), and OER Africa. The project was funded by the Bill and Melinda Gates Foundation Grand Challenges Round 4.

\section{B. The AgShare Approach}

The AgShare vision is to contribute to the development of healthier and wealthier livestock-based communities in Africa by disseminating knowledge, skills, and community service through an innovative information loop system for OER-based research, education, and knowledge.

The AgShare mission is two-fold: (1) to develop teaching and learning materials for two OER modules in two master of science (MSc) degree programs at Makerere: a milk production and hygiene module for the masters in Livestock Development, Planning, and Management (MLD), and a management and marketing of milk and milk products module for the masters in Agri-business Management (M Agbus Mgt); and (2) to implement the use of OERs by different stakeholders along the dairy value chain.

In line with the program's mission, five objectives were identified for the first phase of AgShare at Makerere University:

1. Strengthen faculty and MSc student competencies in the utilization of OER approaches in the dairy value chain.

2. Develop a plan for revising and creating OER-based milk hygiene and marketing modules for the MLD and M Agbus Mgt.

3. Train MSc graduates capable of facilitating positive change in the dairy value chain.

4. Assess the impact of the AgShare multi-stakeholder information loop and OER on the dairy value chain after a 12-month intervention period.

5. Conduct training and feedback sessions with model farmers, who will take the lead and share training with other farmers, in a self-empowering community approach.

Completion of these objectives would yield outputs in the university structure (a framework for the development of teaching modules using graduate students as agents of change in information loop systems between academia and outside stakeholders), university curricula (teaching modules based on field examples and feedback from multi-stakeholders through the information loop system), graduate students (MSc graduates trained in the development and use of OER curricula, using data from the baseline studies), and research (a list of indicators--from baseline studies--that can be used to demonstrate program effects on the dairy value chain; scholarly papers submitted to journals or published as proceedings for scientific conferences). In addition, Makerere faculty would be sensitized and re-oriented in OER approaches regarding the needs to address gaps in curriculum in the dairy value chain. Importantly, the targeted multi-stakeholder groups (e.g., farmers, community leaders) would also be empowered to engage as partners in OER learning to work to improve the performance of the dairy value chain. 


\section{IMPLEMENTATION OF AGSHARE PHASE I}

\section{Infrastructure and Planning at Makerere}

\section{a. At the University Level:}

The COVAB, College of Agriculture and Environmental Sciences, College of Natural Resources, and the Department of Food Science and Technology were contacted to participate in the initial planning of the AgShare project. Opportunities were advertised for students to apply for graduate training at the master's level within the framework of the AgShare project at Makerere University according to university guidelines. Several students were interviewed, and the top two were selected as the first AgShare student researchers.

\section{b. In the Community:}

The AgShare team conducted meetings with the Kiruhura District's administration, production office, and the National Agricultural Advisory Services Office to plan the most effective way of implementing AgShare training activities. The meeting was organized by district local council representative of the Kenshunga sub-county, the chairperson of the Ankole Dairy Products Cooperative Union, and academics from the Department of Agribusiness and Natural Resource Economics at Makerere. The meeting was attended by the chairperson of the Local Council Five (LC V), district local council representatives, the district production officer, and the Ankole Dairy Product Cooperative union chairperson. In this meeting, it was agreed that dairy farmers should be organized into marketing groups, and the district administration should intervene for the proper administration of these farmer organizations. The chairperson of the LC V promised to work out a plan with Makerere and meet with the president of the Republic of Uganda, a resident and farm owner in Kiruhura District, for additional information regarding the dairy sector and milk marketing.

\section{Identifying Needs for Improving the Dairy Value Chain Through the Baseline Study}

Makerere, in collaboration with Michigan State University (MSU), conducted an analysis of the dairy value chain to identify specific needs to address in order to improve the performance of the dairy value chain from farm to table, and to document the indigenous skills and knowledge of dairy value chain stakeholders in Uganda. The baseline study was conducted using two approaches: (1) focus group meetings were conducted with stakeholders along the entire dairy value chain and (2) visits to individual farmers to document the different milk marketing channels used to sell their milk and to assess the status of dairy farms in terms of milk productivity and on-farm milk processing.

The major objective of the focus group discussions was to capture broader views of farmers, traders, and processors about the dairy value chain. During the discussions, traders, farmers, and processors were divided into two groups. In each group, a secretary recorded group contributions for given questions and then presented the group's views in the plenary session for further discussion. The focus groups discussed several questions ranging from milk production, quality milk handling, on-farm milk processing, challenges facing processing, processing opportunities, as well as marketing of milk and processed dairy products like ghee, cream, and yogurt. It was through these focus group discussions that farmers, traders, and processors shared and exchanged their perceptions about opportunities, challenges, and the way forward in respect to dairy value chain improvement.

In addition to the focus group meetings, the research and training team from Makerere visited individual dairy farms in the sub-counties of Kinoni, Keshunga, Kikatsi, and Rwemikoma in the Kiruhura District, using formal structured questionnaires to collect baseline data from each farm. The dairy farmers visited engaged in several dairy chain activities, including milk production, on-farm milk processing, and involvement in trading milk and dairy products. Farmers were divided into two categories: farmers that sold milk through the formal marketing channel and those that sold to the informal marketing channel. At the sub-county level, paired matched sampling was used to select farmers from each category for 
participation in the AgShare intervention program: 60 farmers were interviewed in each sub-county for a total sample of 240 farmers.

\section{Developing the Information Loops}

\section{a. The Action Research-Results-Interventions Loop for Makerere University}

The action research-results-interventions information loop at Makerere University involves (a) action research directed at the dairy value chain conducted by university faculty and graduate students; (b) interpretation of results from action research into materials for use in OERs for student training; and (c) development of interventions based on the results of action research to effect positive changes to the dairy value chain (figure 1). Interventions include specific activities or programs to use on participating farms and educational materials for stakeholders that will be provided as OERs.

To initiate the information loop at the university, researchers from Makerere and MSU used the findings from analyses of the baseline data to develop educational modules to add to the curricula there and to create training materials for dairy value chain stakeholders (farmers and traders). The training materials were focused on knowledge sharing, covering the improvement of dairy farm management and productivity, quality milk handling, on-farm milk processing, and strategic milk and dairy product marketing.

\section{b. Graduate Students as Links Between University and Stakeholder Information Loops}

The MSc students were instrumental as links between the university and stakeholder information loops. These students were engaged in action research, including data collection through participation in the focus group meetings, through the administration of questionnaires during the field visit interviews with dairy farmers, and through the collection of biological samples to determine the quality and safety of milk as well as the existence of cattle diseases that would affect those attributes of the milk. After data collection and laboratory analysis of biological samples, the students worked with faculty researchers at Makerere to develop on-farm interventions for farmers, OER training modules for the university, and OER training modules for stakeholders. Once these modules were developed, the MSc students delivered the training materials to the farmers and assisted them in the implementation of interventions on their farms. The interventions consisted of information packages on methods to improve the milk production, quality, and safety; decrease milk spoilage; increase value addition to their dairy production (e.g., increasing yogurt production); and increase the marketability of milk and milk products. During the 12month course of the intervention period, the students made monthly visits to each farm to monitor the effectiveness of interventions, address questions and concerns from the farmers and other stakeholders, and provide updates and additions to the stakeholder training modules as soon as new information was available through the university information loop.

\section{c. The Education-Interventions-Assessment Loop for Stakeholders}

After the development of interventions and training materials at the university level, AgShare researchers conducted training sessions with participating farmers. The overall goal of the training program was to share knowledge and skills with dairy value chain stakeholders and contribute to the indigenous knowledge and skills. AgShare would contribute to the improved efficiency of the dairy value chain through knowledge, skill, and community service exchange between dairy farmers and Makerere University.

With the help of the chairperson of the Kiruhura dairy farmers' association, milk producers, processors, and traders were organized and two training workshops were developed for each of the three major stakeholder groups (milk producers, on-farm milk processors, and milk traders). These training workshops were conducted in collaboration with the Dairy Development Authority (DDA), East African Dairy Development (EADD), and a dairy business development service provider (BDS). It was anticipated that trained farmers and traders would soon be registered with the DDA since the training would be conducted in collaboration with the DDA and EADD. 
The first two-day-long training session strove to document the indigenous skills and knowledge of dairy chain stakeholders; to develop and share an integrated knowledge and skills with stakeholders that could lead to efficiency of the chain; to equip dairy farmers with functional farm management, milk handling practices, and appropriate on-farm milk technologies; and to expose farmers, traders, and processors to strategic milk marketing and management. Specific focus was given to quality milk production, handling and processing, as well as equipping dairy farmers doing on-farm milk processing with appropriate technologies for processing milk products.

The second workshop, also two days in length, was to disseminate study results to stakeholders and collect feedback from stakeholders regarding the performance of AgShare interventions (stakeholder education and milk processing technology) for their needs. The trainees were awarded certification by the Department of Agribusiness and Natural Resource Economics in collaboration with the Uganda Dairy Development Authority and the East African Dairy Development's Business Development Service. The awarded certificates authorizes trainees to check for milk quality, advise other stakeholders involved in the dairy value chain, and take legal actions in situations of improper milk handling by actors in the dairy value chain.

After implementation of interventions and trainings, researchers returned to the farms to determine the effectiveness of the AgShare approach in terms of positive impacts on individual stakeholders and the dairy value chain as a whole. Two surveys were conducted to capture project impact on farmers in terms of attitude, knowledge, skills, and behavior: modifying attitudes drives behavior (knowledge and skills count for little if the appropriate attitudes are not in place); imparting knowledge to stakeholders allows them to develop better-informed management strategies to improve their component of the dairy value chain; developing skills creates better management of production and marketing; and changing behaviors utilizes the knowledge and skills stakeholders gained through participation in AgShare. An agricultural expert with extensive relevant experience was contracted to compile a dairy-specific questionnaire, and the survey instrument was modified by Makerere University staff based on their working knowledge of which questions would be most applicable to the farmers in the AgShare Program. The MSc students, under the supervision of Makerere University faculty, administered both surveys through in-person interviews. Results from this assessment were then used to direct action research at the university level to further improve performance of the dairy value chain.

\section{Assessing the Impact of AgShare}

The impacts of AgShare at the university (teaching and learning), in the community (project acceptance), and the dairy enterprise of participating farmers were assessed using both qualitative and quantitative methods. Qualitative assessments were conducted by an independent consultant (Ken Harley, University of Pretoria) and relied on participants' accounts of their own before-and-after AgShare experiences. These accounts were collected through on-site interviews that took place at the end of the 12-month intervention period. The quantitative assessments were conducted by AgShare researchers at MSU and Makerere University.

To assess the impact of the AgShare approach on teaching and learning, an independent consultant conducted in-person interviews of academic staff and students. During interviews, academic staff and students were invited to comment, in an open-ended way, on their experiences of using the new OER. Notes were taken to record responses, with as many key utterances as possible recorded as quotes. To evaluate the acceptance of the AgShare program in the community, qualitative assessments were made by the independent consultant based on in-person interviews of extension agents, field veterinarians, farmers, milk processors, and milk buyers. Open-ended responses were collected from stakeholders to capture their experiences working with AgShare researchers, the presentation and quality of educational materials provided by AgShare, and the interventions developed by AgShare to improve different aspects of the dairy value chain. In addition, extension agents, field veterinarians, milk processors, and milk buyers were asked to comment on how AgShare training influenced participating farmers and how effective 
AgShare training and interventions were in improving farm milk production and quality. Again, notes were taken to record responses, with as many key utterances as possible recorded as quotes.

The quantitative assessments of the impact of AgShare were conducted by AgShare scientists and graduate students, and included the comparison of different indicators measured at the beginning and end of the 12-month intervention period. These indicators included measures of milk quality and safety (somatic cell count, presence of harmful bacteria), cattle diseases that affect production and milk quality (mastitis and brucellosis), level of milk production per cow, farm hygiene, quantities of milk discarded due to spoilage, quantities of milk used for producing other dairy products (ghee, yogurt), and prices received for milk and other dairy products. Results from the quantitative assessments are being prepared for publication in refereed scientific journals, and parts of these assessments were used by the graduate students in their research dissertations.

\section{RESULTS}

\section{A. Impact of AgShare at University and Stakeholder Communities}

\section{OER-based Training of MSc Students}

The two MSc students pursued different research programs in their participation of the AgShare Program. These students brought key benefits to the project as "drivers" of the on-farm case studies used for development of OER content. The first student conducted action research leading to an MSc degree in Livestock Development, offered by the COVAB. This student collected case material that was used to develop an OER course module in milk hygiene and safety. The second student conducted action research leading to an MSc degree in Agribusiness Management, offered by the College of Agriculture and Environmental Sciences, and collected case material that was used to develop an OER course module in dairy agri-business. Both course modules are available on the OER Africa website (http://www.oerafrica.org/agshare/AgShareHome/tabid/1290/Default.aspx).

\section{Graduate Student Involvement in AgShare and OER Development}

The merits of apprenticeship in research are widely acknowledged in the academic world but very seldom practiced because of constraints of time and staff/student ratios, and by working in the field with experienced researchers, the AgShare student-researchers affirmed the value of their apprenticeships. The student-researchers also gained experience in developing teaching materials for a diverse audience as well as in developing content for formal publications other than their theses. In addition, the studentresearchers stressed ways in which their personal skills and growth had been enhanced, including learning to access OER and other resources; increasing confidence in their interviewing and writing skills; developing social skills in dealing with stakeholders; and learning to work in a team.

\section{Institutionalization of OER at Makerere University and Other Universities}

As other investigators have reported [3, 4], OER offers opportunities and challenges in higher education. At present, the use of OERs is viewed as a powerful teaching tool and as a generator of opportunities for research and education at Makerere University. Eight faculty members not involved in the project at Makerere University were interviewed individually for their opinions about AgShare and the use of OER, and after seeing AgShare in action, four academic staff members reported having already begun developing their own OER. While Makerere has promoted OER in the dairy value chain pilot across several departments and at the other AgShare universities, the general view of the other AgShare institutions was that impact assessment of the institutionalization of OERs was premature at this time.

\section{Community Stakeholders and AgShare}

The AgShare team at Makerere trained a total of 42 dairy value chain stakeholders in the Kiruhura District. Among the 42 trainees, 32 were dairy farmers that were both milk producers and on-farms processors, and 10 were traders dealing in the marketing of milk (processors, operators of milk collection centers, and bike milk vendors). Almost half of the trainees were recruited through the Amate Gaitu 
Cooperative or by the AgShare project officer, and the remainder were recruited by friends or family members, the local village chief, or local veterinarians. Over $90 \%$ of trainees hoped to learn more about dairy production systems through AgShare training, with the balance hoping to learn more about ways of adding value to the commodity.

A workshop to disseminate survey results to stakeholders was attended by dairy farmers, milk traders, and local government staff. The workshop highlighted the performance of their farms, challenges faced, current opportunities, and strategy development to move forward in regard to improving dairy value chain efficiency. In the workshop, both farmers and traders reached consensus that farmers need to be organized to benefit from dairying, resulting in the formation of a dairy farmers' marketing organization. Although just over half of the participating stakeholders had been positive about the dairy project at its inception, all gave overwhelmingly positive feedback at its conclusion: one of the workshop moderators noted "There was an overwhelmingly positive feedback about the impact of the stakeholder meetings, with all respondents indicating that they benefitted from these sessions."

In addition to the workshops, on-farm interview sessions were conducted to capture project effect on farmers. The interviews were designed to measure impact in terms of stakeholder attitudes, knowledge, skills, and behaviors. Stakeholders indicated that AgShare promoted many new attitudes that imbued farmers with a sense of "liberation and fulfillment." Their views mattered, and they felt affirmed. The shift to market-orientation - the farm as a business - was a fundamental shift that enabled other project impacts. There was a new awareness and openness in relation to what technology offers and a realization of the power of farm management. New forms of knowledge were evident in the power of choice (e.g., the relationship between value of the product and quantity); knowledge of systems (e.g., the leverage of collective action); farm management (e.g., record keeping and costing); primary production (e.g., ways of increasing yields); and the effects of government policy. Clear accounts were given of new production and farm management skills. Record keeping was a key new skill as it provides a solid foundation for decision-making. For several farmers, behaviors changed as they applied their new knowledge and skills, and AgShare was a life-changing experience: the greatest impact of AgShare was made in changing their farming paradigm "from farm to firm." Other comments indicated that most farmers indicated that they had actually applied what they learned to their individual farm businesses, and seen benefit from these lessons. All respondents reported benefiting from the one-on-one feedback sessions for laboratory reports of disease status of their dairy herd.

There was ample evidence that stakeholder attitudes, knowledge, skills, and behaviors had been positively impacted by participation in AgShare. One finding was that the formation of farmers' cooperative unions depended heavily on levels of formal education, dominant market players, and farmers' socio-economic and dairy characteristics. Dairy farmers that sold milk through cooperatives were economically better off in terms milk volumes, herd size, dairy, and farm management practices than their counterparts. AgShare training helped motivate farmers with no formal education to participate in cooperative unions, improving their future prospects. Additionally, the AgShare studies demonstrated that dairy farmers had functional traditional knowledge and skills regarding value addition, primarily in the production of ghee and fermented yogurt on their farms. Armed with this knowledge, interventions were positioned to integrate modern processing practices in ghee and yogurt production to improve the quality and quantity of the onfarm production. In particular, the processing of ghee was a tradition and was regarded as a women's activity; improvements to on-farm ghee production would improve the contributions of women to farm income and their status in the dairy and agricultural industry.

The quantitative assessment of the impact of interventions through the education-intervention-assessment information loop found that AgShare training highly influenced farmers. AgShare researchers identified this directly through farmer interviews, and this was confirmed by observations from extension agents, field veterinarians, milk processors, and milk buyers. These findings were reinforced by anecdotal evidence provided by academics and student-researchers during the independent consultant's site visits for the external impact assessment of AgShare. For example, farmers benefitted by moving into valueadded milk products: while profits on a liter of milk averaged 200 Uganda shillings, profits rose to 600 
800 Uganda shillings when the milk was used to produce yogurt. One farmer was so grateful for this increase in profits that he rewarded a student-researcher who had helped him write successful business plans with a generous gift of two cows. All trained milk producers, processors, and traders had a strong willingness to adopt new technologies (production and processing) and new marketing strategies as a result of AgShare, which suggests that dairy farmers have wanted but had not been receiving such functional skill-oriented training.

\section{Impacts on the Dairy Value Chain}

Almost $92 \%$ of all respondents who participated in the project indicated that it was beneficial; all reported improvements in their dairy production systems. Preliminary assessments have indicated improvement in milk quality (as determined by lower total somatic cell count), milk safety (as measured by the prevalence of mastitis and brucellosis), reduced spoilage of milk, and higher prices received for milk and yogurt for farmers who took part in the AgShare Program.

The AgShare training interventions in Kiruhura dairy chain led to the strengthening of already existing farmers' cooperative unions. The cooperatives that benefited from the project were Amate Gaitu, the Ankole Dairy Products Cooperative, and the Kazo Dairy Products Cooperative Union. The trained farmers, processors, and traders also formed a new cooperative whose objective was to streamline milk and dairy products marketing with the establishment of a strong understanding between all stakeholders.

AgShare also established strong collaborations with the district Executive, Production, and Agricultural Advisory Offices, the Uganda Dairy Development Authority, and East African Dairy Development and Business Development Service providers. During AgShare meetings with these dairy stakeholders, it was agreed that suitable dairy policies needed to be put in place to improve the effectiveness and efficiency of the dairy value chain. The meeting concluded that a proper program discussed with the president of the Republic of Uganda would be developed for policy streamlining, effective implementation of AgShare activities, and seeking additional funding for these initiatives.

\section{B. Effects of Institutionalization of the AgShare Model}

\section{OER as a Means of Meeting Education Needs}

Universities participating in AgShare are no different from other institutions experiencing the pressures of increased student numbers in the face of diminishing government subsidies with attendant resource constraints. Staff in the AgShare pilots reported increased interest by university management and the national government in promoting "distance" learning, with awareness that such initiatives would need to be underpinned by materials development. The AgShare model for development of OER learning materials is being held up as the example for broader initiatives to emulate. While this might be a case of OER appeal at an instrumental or even at a reactive level, there were definite indications that other institutions in the region are viewing the AgShare model in more proactive ways. In addition, the cost of higher education has been on the rise globally. As more universities adapt OER, the cost of higher education can be reduced [6], which will be particularly welcome news in developing countries.

\section{OER as a Way of Re-positioning the University}

University mission statements are typically developed around the pillars of research, teaching, and community development, often supporting the stereotypical "ivory tower." AgShare provides a model founded on field-based research carried out by staff and students, with research serving the dual purpose of supporting research-based teaching and delivering improved field practice back to the farming community. Makerere has gone beyond the potential of the AgShare model in the COVAB while the university was pressured from the outside and troubled by serious internal doubts about its relevance; AgShare arrived as a model that anchored academic excellence in transformation of the community. AgShare has the structural elements of a community of practice [7], which differs from a project team in significant ways. A conventional project team is driven by deliverables with shared goals and milestones, and it is dissolved once its mission is accomplished. In contrast, a community of practice is often 
organically created: memberships may change, and members may take on new roles within the community as interests and needs arise. The dynamic capacity of the AgShare community of practice allowed the program to adapt to changing needs of both the university and the stakeholder communities. As such, AgShare became seen as "The Model" to make the university relevant to society-locally, regionally, and nationally.

While Makerere University was already inclined towards a more relevant developmental posture prior to AgShare, AgShare funding helped actualize the vision and provided the conceptual model for cooperation. This vision has been institutionalized in AFRISA (Africa Institute for Strategic Animal Resource Services and Development). Funded by the Republic of Uganda Ministries of Education and Agriculture and approved by the Makerere University Council, AFRISA provides a "platform of training and research to innovation actors in animal resource sector" that moves education from the ivory tower to the Academic-Community-Public-Private Partnership (ACP3) model. Courses offered on the AFRISA website include certificates for Basic and Professional Skills; diploma, bachelor's degree, and master's degree programs; and postgraduate courses. In the dairy value chain, skills certificates are offered in ice cream production, yogurt production, butter and ghee production, artificial insemination techniques, farm information and records management, and small-holder milk production and marketing. With several other projects and funders listed on the AFRISA home page, it is important to recognize the significant contribution of AgShare. As the dean of COVAB stated in the AgShare impact assessment report to the Gates Foundation [7], "AgShare was the seed which kept producing more seeds," including AFRISA.

\section{CONCLUSIONS}

The AgShare approach at Makerere University, using action research in continuously-updated information loops of real-world data and information for teaching and the development of OER for university and stakeholder education, has been unique in that its impact has been achieved across a range of stakeholders. The program has shown important benefits to those involved in teaching and learning about the dairy value chain at the university and in communities, to those engaged in production, processing, and marketing of milk and other dairy products. The action research model of training graduate students is gaining support at Makerere University as a whole, and the dynamic creation of curricula using OER modules is likely to be the future of this university.

\section{REFERENCES}

1. Rosegrant, M.W., Ringler, C., Benson, T., Diao, X., Resnick, D., Thurlow, J., Torero, M., and Orden, D. Agriculture and Achieving the Millennium Development Goals. International Food Policy Research Institute (IFPRI), Report 32729-GLB. http://www.ifpri.org/sites/default/files/publications/AgMDG.pdf.

2. Mubiru, S.L., Tenywa, J.S., Halberg, N., Romney, D., Nanyeenya, W., Baltenweek, I., and Staal, S. Categorization of the Dairy Production Systems: A Strategy for Targeting Meaningful Development of the Systems in Uganda. Livestock Research for Rural Development, 19(7) (2007).

3. Atkins, D.E., Brown, J.S., and Hammond, A.L. A Review of the Open Educational Resources (OER) Movement: Achievements, Challenges, and New Opportunities. The William and Flora Hewlett Foundation (2007). http://www.hewlett.org/uploads/files/ReviewoftheOERMovement.pdf.

4. Yuan, L., MacNeill, S., and Kraan, W. Open Educational Resources-Opportunities and Challenges for Higher http://wiki.cetis.ac.uk/images/0/0b/OER Briefing Paper.pdf.

5. Wenger, E. Communities of practice a brief introduction (2006). http://www.ewenger.com/theory/index.htm.

6. Wiley, D. On the Sustainability of Open Educational Resource Initiatives in Higher Education. (2006). http://www1.oecd.org/edu/ceri/38645447.pdf. 
7. Harley, K. AgShare Planning and Pilot Project Impact Study (2012). http://www.oerafrica.org/agricultureoer/AgricultureResources/ResultsPage/tabid/1784/mctl/Details/ id/39276/Default.aspx.

\section{ACKNOWLEDGEMENTS}

The activities of the AgShare Program reported here were supported by funding from the Bill and Melinda Gates Foundation-Grand Challenge 4. The authors would also like to thank the following institutions and individuals for their contributions to the project: Makerere University, AFRISA (African Institute for Strategic Animal Resource Services and Development), the College of Agriculture and Environmental Sciences, College of Natural Resources, and the Department of Food Science and Technology; Michigan State University-College of Veterinary Medicine, Christine Geith and Karen Vignare of the MSU Global Initiative; Neil Butcher of OER Africa; SAIDE (South African Institute for Distance Education); and Ken Harley, University of Pretoria.

\section{ABOUT THE AUTHORS}

John B. Kaneene is a University Distinguished Professor of Epidemiology and director of the Center for Comparative Epidemiology in the College of Veterinary Medicine, Michigan State University, USA.

Stevens Kisaka is an assistant lecturer in the College of Veterinary Medicine, Animal Resources, and Biosecurity, Makerere University, Uganda.

Paul Ssajjakambwe is an assistant lecturer in the College of Veterinary Medicine, Animal Resources, and Biosecurity, Makerere University, Uganda.

RoseAnn Miller is a research assistant in the Center for Comparative Epidemiology, College of Veterinary Medicine, Michigan State University, USA.

John D. Kabasa is a professor and principal of the College of Veterinary Medicine, Animal Resources, and Biosecurity, Makerere University, Uganda. 